Collection: Cost Action E29 Meeting 2008- Istanbul (Turkey)

Future Monitoring and Research Needs for Forest Ecosystems

Guest Editor: Marcus Schaub (WSL, Birmensdorf, CH)

\section{QA/QC activities and ecological monitoring in the Acid Deposition Monitoring Network in East Asia (EANET)}

\author{
Sase $H^{(1)}$, Nakayama $S^{(1)}$, Leong CP ${ }^{(1)}$, Kamisako $M^{(1)}$, Luangjame $J^{(2)}$, \\ Garivait $H^{(3)}$, Visaratana $T^{(2)}$, Kietvuttinon $B^{(2)}$, Ueda $H^{(1)}$
}

An overview is presented of Quality assurance/Quality control QA/QC activities and current features of the ecological monitoring in the frame of the Acid Deposition Monitoring Network in East Asia EANET. It is stressed that standardization of the methodologies applicable for new topics, such as the catchment analysis and ozone impacts, should be investigated for future monitoring.

Keywords: EANET, Acid deposition, Soil monitoring, Catchment, Ozone

\section{Introduction}

The Acid Deposition Monitoring Network in East Asia (EANET) began its regularphase activities in January 2001. Thirteen countries participated in the network. The Acid Deposition and Oxidant Research Center in Japan is designated as the Network Center for EANET (NC). Monitoring of wet deposition, dry deposition (air concentration), soil and (forest) vegetation, and inland aquatic environment has been implemented following the relevant quality assurance and quality control $(\mathrm{QA} / \mathrm{QC})$ procedures.

In addition to the regular monitoring, several research projects have been promoted in different climatic zones by $\mathrm{NC}$ and the relevant organizations in the participating countries (e.g., Sase et al. 2005, Sase et al. 2008) The QA/QC procedures of EANET allow

(1) Acid Deposition and Oxidant Research Center, 1182 Sowa, Nishi-ku, Niigata, 9502144, Japan; (2) Royal Forest Department, 61 Phaholyothin Road, Bangkok 10900, Thailand; (3) Environmental Research and Training Center, Technopolis, Amphoe Klong 5, Klong Luang, Pathumthani 12120 , Thailand

\section{(a) Hiroyuki Sase (sase@adorc.gr.jp)}

Received: Mar 13, 2008 - Accepted: Dec 09, 2008

Citation: Sase $\mathrm{H}$, Nakayama S, Leong CP, Kamisako M, Luangjame J, Garivait $\mathrm{H}$, Visaratana T, Kietvuttinon B, Ueda H, 2009. QA/QC activities and ecological monitoring in the Acid Deposition Monitoring Network in East Asia (EANET). iForest 2: 26-29 [online: 2009-01-21] URL:

http://www.sisef.it/iforest/show.php? id $=481$ collection of high quality scientific data for these studies. The outcomes of the research activities will be utilized for further development of the monitoring network.

In this paper, we introduce an overview of the QA/QC activities and current features of the ecological monitoring in EANET.

\section{Implementation of QA/QC activities}

\section{Efforts to achieve high quality data}

As of 2007, 51 and 40 sites have been established for wet and dry deposition monitoring respectively (Fig. 1a). 24 forests have been selected for soil and forest vegetation monitoring, and 10 lakes and 5 rivers have been selected for inland aquatic monitoring meters for each field are shown in Tab. 1.

Technical documents, including manuals and $\mathrm{QA} / \mathrm{QC}$ programs, were developed in 2000 during the preparatory-phase activities of EANET. The QA/QC programs of EANET cover all the activities from site selection to data reporting. The following actions were recommended in the QA/QC programs:

1. development of national QA/QC programs;

2. clear assignment of responsibilities;

3. development of standard operating procedures (SOPs);

4. definition of data quality objectives;

5. implementation of inter-laboratory comparison projects;

6. audit to sites and laboratories by the national centers. Documentation of the activities is promoted in national and international levels according to the recommenda(Fig. 1b). Recommended monitoring para- tions above.

The inter-laboratory comparison projects have been carried out annually for wet deposition since 1998 , for soil since 1999 , for inland aquatic environment since 2000, and for dry deposition (filter pack method) since 2005. In 2006, 31 laboratories of 13 countries participated in the projects on wet deposition, 20 laboratories of 10 countries on dry deposition, 14 laboratories of 9 countries on soil, and 18 laboratories of 9 countries on inland aquatic environment.

A national QA/QC manager is designated in each country to assist the network manager in implementing the monitoring activities. The national QA/QC managers are responsible for the QA/QC activities and data management in the respective countries. A Senior Technical Managers' Meeting is held annually to enable closer communications among them. Moreover, the NC dispatches technical missions to the participating countries to provide opportunities for discussion of technical problems on the monitoring activities. Close communications among the relevant experts in EANET may also contribute to the network $\mathrm{QA} / \mathrm{QC}$.

The data submitted by countries to $\mathrm{NC}$ are checked by an ad hoc data verification group, which consists of experts in the relevant study fields. The verified data are compiled as the annual Data Report of EANET. Moreover, based on the data compiled from 2000 to 2004, the first periodic report on the state of acid deposition in East Asia was published in 2007 (EANET 2008b). All the reports above are available on the web (EANET 2008a).

\section{QA/QC program for soil monitoring}

The QA/QC program for soil monitoring proposed statistical models for soil analysis. The statistical models considered a multistage sampling design on several sampling levels, including area, soil type, plot, subplot, and horizon/layer. A variance at each sampling level and its contribution to the total variance could be estimated by the analysis of variance (ANOVA). The first trial of the ANOVA for the soil data from 2000 to 2004 was reported in the first periodic report of EANET (EANET 2008b). The large contribution of soil types to the data variation was clarified. The information above may be useful to discuss the precision of the soil data.

Analytical errors under repeatability, within-laboratory reproducibility, and reproducibility conditions could also be estimated based on the inter-laboratory comparison project on soil. NC promoted standardization of analytical procedures, and most laboratories have followed the standard procedures. Moreover, by using digital formats, calcula- 


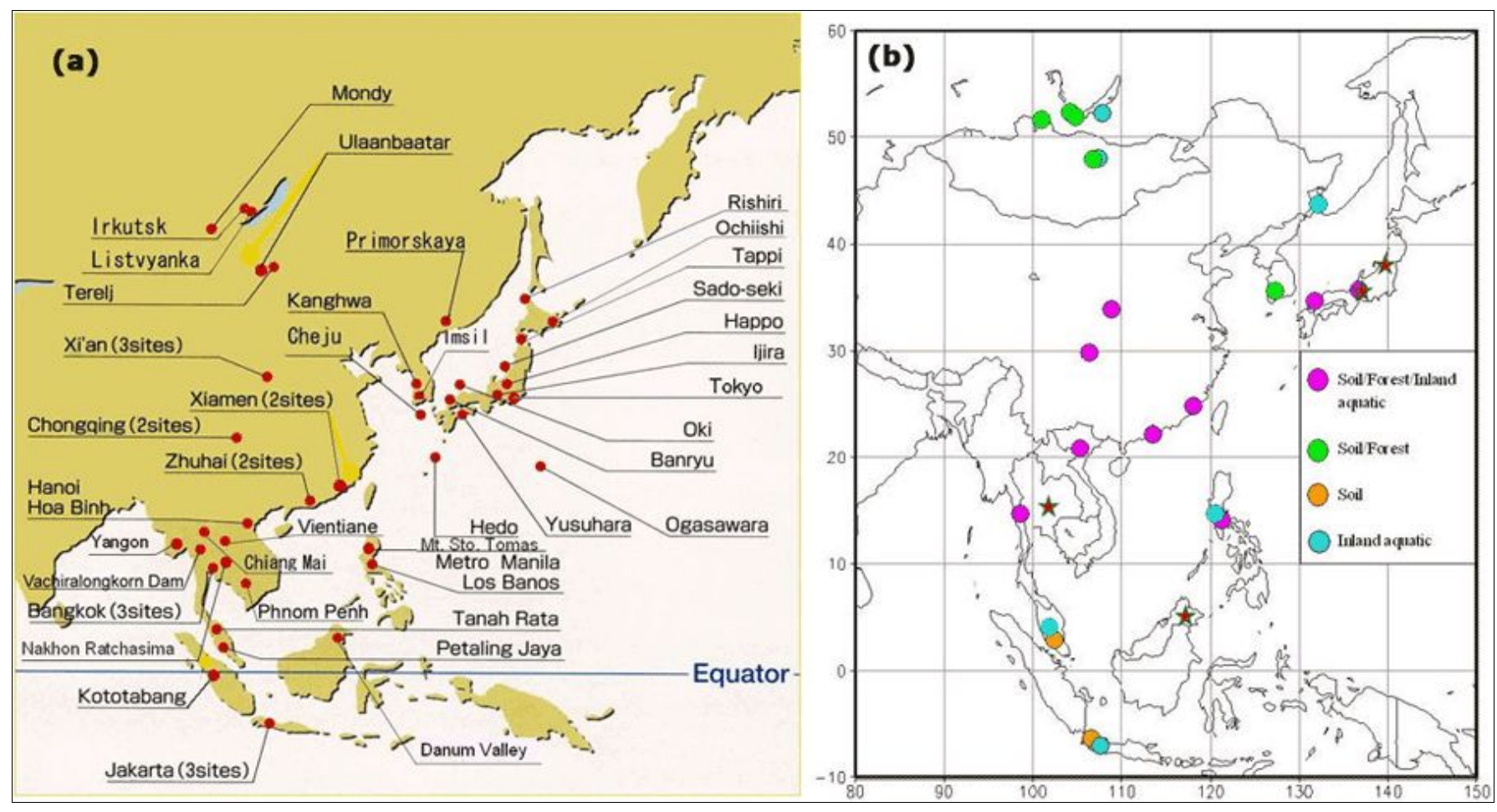

Fig. 1 - Acid deposition monitoring sites (a) for wet and dry deposition and ecological survey sites (b) for soil, vegetation, and inland aquatic environment in EANET (as of 2007). Number of sites for the respective items: Wet deposition, 51; Dry deposition, 40; Soil and (forest) vegetation, 24 forests in 16 areas; Inland aquatic environment, 10 lakes and 5 rivers. Red stars on the map (b) indicate locations of the catchment study sites, namely, Kajikawa study site in Japan, the Lake Ijira Catchment in Japan, Sakaerat SRS in Thailand, and Danum Valley CA in Malaysia.

tion errors were reduced. Coefficients of variance $(\mathrm{CVs}, \%)$ on repeatability and within-laboratory conditions were relatively small for most parameters (Network Center for EANET 2007). It was suggested that the participating laboratories could analyze the parameters with their own standard procedures.
However, CVs on the reproducibility condition were still large especially for exchangeable base cations such as $\mathrm{Ca}$ and $\mathrm{Mg}$ (Fig. 2), while those for $\mathrm{pH}\left(\mathrm{H}_{2} \mathrm{O}\right)$ and $\mathrm{pH}$

Tab. 1 - Recommended monitoring parameters in EANET. Based on the "Guidelines for acid deposition monitoring in east Asia" (EANET 2000).

Wet deposition $\quad$ Rainwater acidity and con- $-\mathrm{pH}$, electric conductivity (EC), $\mathrm{Cl}^{-}, \mathrm{NO}_{3}^{-}, \mathrm{SO}_{4}{ }^{2-}, \mathrm{NO}_{2}^{-}, \mathrm{F}^{-}, \mathrm{PO}_{4}{ }^{3-}, \mathrm{NH}_{4}{ }^{+}, \mathrm{Na}^{+}, \mathrm{K}^{+}, \mathrm{Ca}^{2+}$, (rainwater):

\section{Dry Deposition Air concentrations of}

(air concentration): gaseous and particulate

Soil and vegetation Chemical and physical prop- - Soil: (in forest areas): $\quad$ erties of soil, forest vegeta-

Inland aquatic environments (lake and river water): forms of acidic and basic compounds as well as ozone tion characteristics, and condition of tree decline

$\mathrm{Mg}^{2+}$, heavy metals, $\mathrm{Al}, \mathrm{Hg}$, and organic acids

\section{- Gases:}

$\mathrm{SO}_{2}, \mathrm{O}_{3}, \mathrm{NO}, \mathrm{NO}_{2}, \mathrm{HNO}_{3}$, and $\mathrm{NH}_{3}$

\section{- Aerosols:}

particulate mass concentration $(\mathrm{PM})$ and concentrations of ions $\left(\mathrm{SO}_{4}{ }^{2-}, \mathrm{NO}_{3}{ }^{-}, \mathrm{NH}_{4}{ }^{+}\right.$, and $\left.\mathrm{Ca}^{2+}\right)$

moisture content, $\mathrm{pH}\left(\mathrm{H}_{2} \mathrm{O}\right), \mathrm{pH}(\mathrm{KCl})$, exchangeable base cations $\left(\mathrm{Ca}^{2+}, \mathrm{Mg}^{2+}, \mathrm{Na}^{+}\right.$, $\mathrm{K}^{+}$), exchangeable acidity, exchangeable $\mathrm{Al}$, exchangeable $\mathrm{H}$, effective cation exchange capacity (ECEC), carbonate content (for calcareous soil), total carbon content, total nitrogen content, available phosphate, sulfate, fine earth bulk density, and penetration resistance

- Forest vegetation:

description of trees (name of species, diameter at breast height, and height of tree), understory vegetation survey, survey of tree decline (observation of tree decline, photographic record of tree decline, and estimation of decline causes)

Concentrations of ions due to - Water temperature, $\mathrm{pH}, \mathrm{EC}$, alkalinity (at $\mathrm{pH} 4.8$ baseline), $\mathrm{NH}_{4}^{+}, \mathrm{Ca}^{2+}, \mathrm{Mg}^{2+}, \mathrm{Na}^{+}, \mathrm{K}^{+}$, acids and bases, and some chemical and biological parameters $\mathrm{SO}_{4}^{2-}, \mathrm{NO}_{3}^{-}, \mathrm{Cl}^{-}, \mathrm{NO}_{2}^{-}, \mathrm{PO}_{4}^{3-}$, phytoplankton (diatom species), living organisms other than phytoplankton, epilithic algae, transparency, water color, DOC (if impossible, then $\mathrm{COD})$, total $\mathrm{Al}$, pore water of sediment $\left(\mathrm{SO}_{4}{ }^{2-}, \mathrm{NO}_{3}{ }^{-}\right.$and $\left.\mathrm{NH}_{4}{ }^{+}\right)$, sediment $(\mathrm{Pb}, \mathrm{Pb}-210$, and stable isotope of S) 
Fig. 2 - Comparison with inter-laboratories coefficients of variance $(\mathrm{CV} \%)$ of the past surveys for exchangeable (Ex-) $\mathrm{Ca}, \mathrm{Mg}$, and acidity. The first two digits of the sample numbers represent the years; e.g., No. 061 and 062 were the samples for the year 2006 (Network Center for EANET 2007).

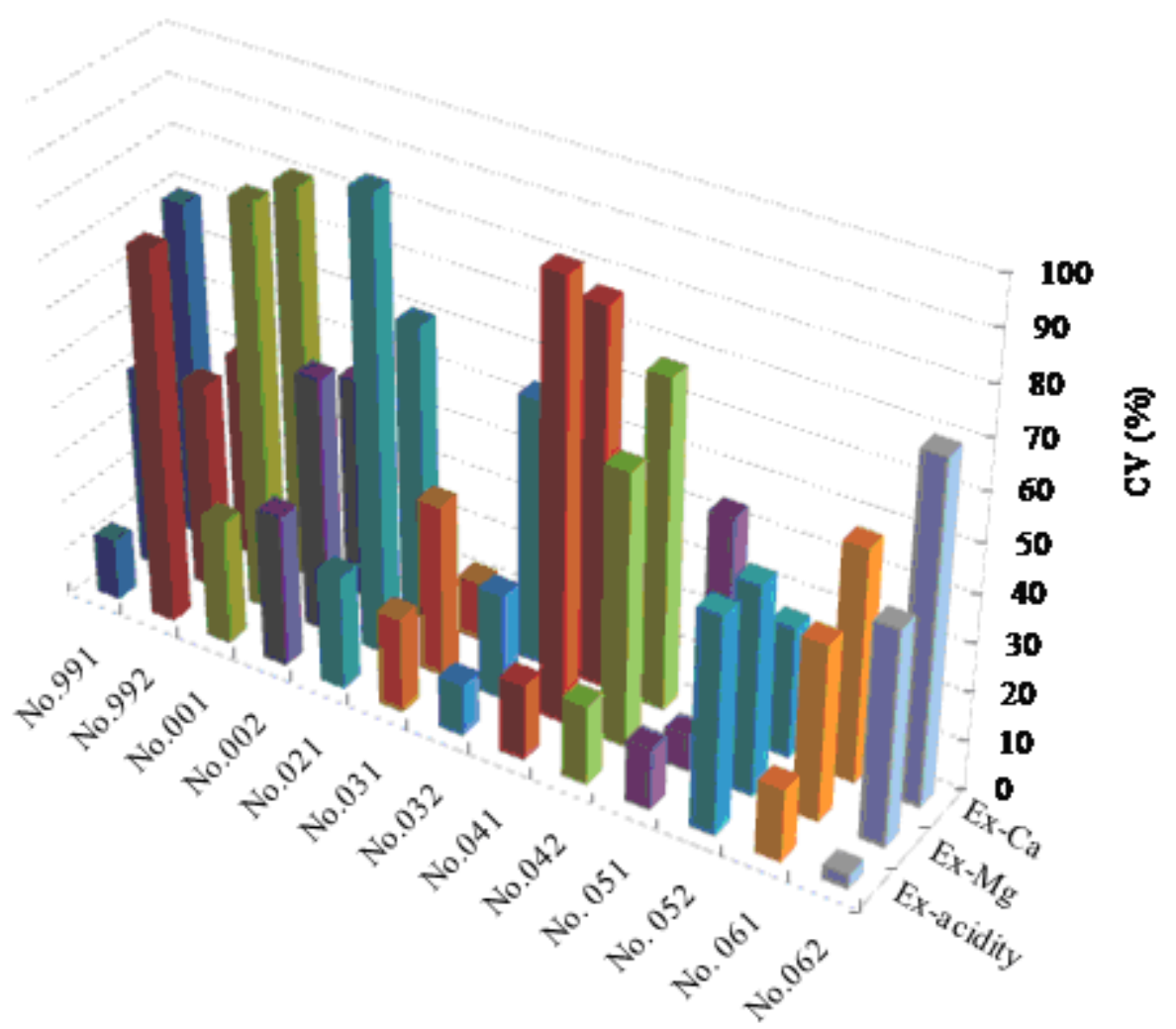

ies are ongoing as the research projects with the EANET countries. Study catchments have been established in Thailand, Malaysia, and Japan, taking into consideration variability of climatic zones and forest types in the East Asian region.

In the case of Thailand, the study catchment has been established in 2005 in a dryevergreen forest in Sakaerat Silvicultural Research Station (SRS), Nakhon Ratchasima Province, in cooperation with the Royal Forest Department, Environmental Research and Training Center, Department of Environmental Quality Promotion of Thailand and Kyoto University in Japan. As for Malaysia, the study catchment has just been established in 2008 in a tropical rain forest in the Danum Valley Conservation Area (CA), Sabah, in cooperation with the Malaysian Meteorological Department and Lancaster University, UK. In Japan, the Kajikawa study site was established in 2002 in a Japanese cedar forest in Shibata City (in the area of the former Kajikawa Village), Niigata Prefecture, in cooperation with the prefectural goval cycles is one of the hot topics on ecological monitoring in EANET. Several case stud- ernment and Niigata University, Japan.

Field surveys on input (atmospheric deposition), output (discharge from a stream) and biogeochemical processes are carried out in these study catchments. The EANET data can be correlated, especially in Sakaerat SRS and Danum Valley CA, since the monitoring sites for wet deposition and dry deposition (air concentration) are located in the vicinity. So far, clear seasonality of atmospheric deposition and elemental flow in the forest ecosystems have been observed in the study catchments (e.g., Sase et al. 2008). Additionally, the similar surveys conducted by the Ministry of the Environment of Japan (MOEJ) in the Lake Ijira Catchment, Gifu Prefecture, can be referenced. This catchment showed evidence of the acidification phenomena in soil and inland water (e.g., Yamada et al. 2007) suggesting effects of atmospheric deposition. Based on the field data above, standardization of observation methods to obtain good quality data and numerical modeling of the ecosystem are currently being discussed for future monitoring.

\section{High ozone concentration}

High ozone concentration and its effects on ecosystems is another recent hot topic in the East Asian region. Several case studies on measurements of ozone concentrations in forest area have been implemented using the Ogawa passive sampler (Hirano et al. 2002, Sase \& Takahashi 2006) in several types of forests in East Asia including the study catchments mentioned above. 
The ozone concentrations in Sakaerat SRS were shown in Tab. 2. The area has two distinct seasons, a dry season from December to March and a wet season from April to November. Ozone concentrations were significantly higher in dry seasons compared to wet season. The highest concentrations of ozone were higher than $60 \mathrm{ppb}$ even in 15day mean values. The mean values in wet season are mostly equivalent to those from April to September in central Europe (ICP Forests 2007), while the mean values in dry season are much higher. Further investigation is necessary on effects of high ozone concentrations in dry season, when plant activities may be relatively limited Moreover, the peak hourly concentrations are generally much higher in the daytime, since ozone concentration generally shows diurnal variation. Assessment of ozone impacts should be discussed in conjunction with standardization of the monitoring methodologies.

\section{Conclusion}

Efforts have been made by various approaches to improve the data quality in EANET. Such efforts should be continued to assure the reliability of the network data Moreover, standardization of the methodolo- gies applicable for new topics, such as the catchment analysis and ozone impacts, should be investigated for future monitoring.

\section{Acknowledgments}

Part of this study was supported financially by the Global Environment Research Fund (C-052 and C-082) of MOEJ.

\section{References}

EANET (2000). Guidelines for acid deposition monitoring in East Asia. EANET Publications, acid deposition monitoring network in East Asia. [online] URL: http://www.eanet.cc/product.html EANET (2008a). EANET Publications, acid deposition monitoring network in East Asia. [online] URL: http://www.eanet.cc/product.html EANET (2008b). Periodic report on the state of acid deposition in East Asia. EANET Publications, Acid Deposition Monitoring Network in East Asia. [online] URL: http://www.eanet.cc/product.html

Hirano K, Maeda H, Saito K (2002). Methods for measurement of $\mathrm{NO}, \mathrm{NO}_{2}, \mathrm{SO}_{2}, \mathrm{O}_{3}$ and $\mathrm{NH}_{3}$ concentration by means of passive samplers (in Japanese), Yokohama Environmental Science Research Institute, Yokohama City, Kanagawa Pref. Japan. [online] URL: http://www.city.yokohama.jp/me/kankyou/mamoru/kenkyu/shiryo/pub /d0001/d0001.pdf
ICP Forests (2007). The condition of forests in Europe - 2007 executive report. Federal Research Centre for Forestry and Forest Products (BFH).

Network Center for EANET (2007). Report on the inter-laboratory comparison project 2006. Acid Deposition and Oxidant Research Center.

Sase H, Bulgan T, Batchuhuluun T, Shimizu H, Totsuka T (2005). Tree decline and its possible causes around Mount Bogdkhan in Mongolia. Phyton 45: 583-590.

Sase H, Takahashi A (2006). Estimating the concentration and deposition of air pollutants in forest areas. In: "Sub-manual on forest vegetation monitoring in EANET". Acid Deposition and Oxidant Research Center, Niigata, Japan.

Sase H, Takahashi A, Sato M, Kobayashi H, Nakata M, Totsuka T (2008). Seasonal variation in the atmospheric deposition of inorganic constituents and canopy interactions in a Japanese cedar forest. Environmental Pollution 152: 1-10. - doi: 10.1016/j.envpol.2007.06.023

Yamada T, Inoue T, Fukuhara $\mathrm{H}$, Nakahara O, Izuta T, Suda R, Takahashi M, Sase H, Takahashi A, Kobayashi H, Ohizumi T, Hakamata T (2007). Long-term trends in surface water quality of five lakes in Japan. Water Air and Soil Pollution Focus 7: 259-266. - doi: 10.1007/s11267006-9076-8 